Article

\title{
Comparative Proteomic Analysis Reveals Key Proteins Linked to the Accumulation of Soluble Sugars and Organic Acids in the Mature Fruits of the Wild Malus Species
}

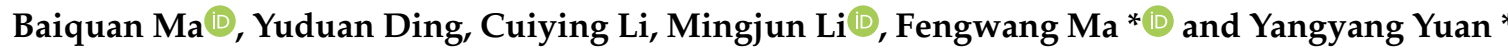 \\ State Key Laboratory of Crop Stress Biology for Arid Areas/Shaanxi Key Laboratory of Apple, College of \\ Horticulture, Northwest A\&F University, Yangling 712100, Shaanxi, China; bqma87@nwsuaf.edu.cn (B.M.); \\ dingyuduan@nwafu.edu.cn (Y.D.); lcy1262@nwsuaf.edu.cn (C.L.); limingjun@nwsuaf.edu.cn (M.L.) \\ * Correspondence: fwm64@nwsuaf.edu.cn (F.M.); yy.yuan@nwsuaf.edu.cn (Y.Y.); \\ Tel./Fax: +86-029-8708-2648 (F.M.)
}

Received: 24 October 2019; Accepted: 8 November 2019; Published: 11 November 2019

\begin{abstract}
Soluble sugars and organic acids are the main determinants of fruit organoleptic quality. To investigate the genes responsible for the soluble sugar and organic acid contents of apple fruits, a label-free proteomic analysis involving liquid chromatography (LC)-mass spectrometry (MS)/MS was conducted with the fruits of two Malus species, M. sargentii and M. niedzwetzkyana, which exhibit significant differences in soluble sugar and organic acid contents. A total of 13,036 unique peptides and 1,079 differentially-expressed proteins were identified. To verify the LC-MS/MS results, five candidate proteins were further analyzed by parallel reaction monitoring. The results were consistent with the LC-MS/MS data, which confirmed the reliability of the LC-MS/MS analysis. The functional annotation of the differentially-expressed proteins, based on the gene ontology and Kyoto Encyclopedia of Genes and Genomes (KEGG) databases, revealed that they were mainly related to biological processes and cellular components. Additionally, the main enriched KEGG pathways were related to metabolic processes. Moreover, 31 proteins involved in soluble sugar metabolism, organic acid metabolism, and $\mathrm{H}^{+}$-transport were identified. The results of this study may be useful for the comprehensive characterization of the complex mechanism regulating apple fruit-soluble sugar and organic acid contents.
\end{abstract}

Keywords: apple; soluble sugars; organic acids; proteomics; parallel reaction monitoring

\section{Introduction}

Soluble sugars and organic acids are crucial determinants of fruit tastes, which combine with aromas to considerably influence the overall organoleptic quality of fruits [1,2]. Soluble sugars are the main source of carbon and energy in organisms, and are important for plant growth and development [3]. In fruits, soluble sugars mainly comprise sucrose, fructose, and glucose. Sucrose is commonly translocated to sink organs (carbon-demanding organs) via long-distance transport in phloem $[4,5]$. Three major organic acids (malic, citric, and tartaric acids) accumulate in most fruits, and their concentration in mature fruits is determined by the balance among acid synthesis, degradation, utilization, and compartmentalization in subcellular organelles [6,7]. The predominant organic acids in mature fruits vary among species. For example, malic acid is the major organic acid in apple, loquat, and pear [2,8-10], whereas citric acid is the predominant organic acid in citrus fruits [11].

Proteins are vital parts of living organisms and have diverse functions. Proteomics refers to the study of the proteins and includes investigations of protein expression levels, post-translational 
modifications, protein-protein interactions, and interactions between proteins and other biomolecules. Thus, proteomic analyses are important for studying biological systems [12]. In recent decades, approaches based on stable isotope labeling and label-free techniques have been used to conduct quantitative proteomic research [13]. Traditionally, methods involving two-dimensional electrophoresis coupled with mass spectrometry (MS), tandem MS (MS/MS), or liquid chromatography (LC)-MS/MS have been commonly used for quantitative proteomic investigations, including large-scale quantitative analyses [14]. To avoid the ion suppression effects of the MS signal for a particular peptide among co-eluting species, the LC-MS/MS approach with stable isotope-labeling techniques has been widely used for relative quantifications $[15,16]$. Although this strategy can accurately quantify protein abundances, labeling with a stable isotope is expensive and requires specific software and expertise to analyze the data. Moreover, some labeling procedures involve complex processes and yield artifacts $[17,18]$. As an alternative, label-free methods based on relative peptide peak intensities and protein abundances were recently developed. This label-free approach is applicable for any proteomic sample and does not require isotopes for quantification [19]. More recently, two targeted proteomic methods, selected reaction monitoring (SRM) and parallel reaction monitoring (PRM), have become prevalent. There may be several advantages to PRM over SRM, including greater specificity, higher tolerance for co-isolated background peptides/species, and no need for a preselection step [20-22].

Apple (Malus $\times$ domestica Borkh.) is one of the most important fruit crops in temperate regions, and its genome sequence has been released [23,24]. Apple fruits contain many components beneficial for human health, including soluble sugars, organic acids, and amino acids. The balance between soluble sugars and organic acids is responsible for the taste and flavor of apple fruits [25-27]. In apple fruits, the predominant soluble sugars are glucose, fructose, sucrose, and sorbitol, whereas the major organic acid is malic acid, which accounts for up to $90 \%$ of the total organic acid content $[2,9,28]$. A recent analysis of the organic acids in the mature fruits of 111 apple accessions (53 apple cultivars and 58 wild relatives) revealed that malic and citric acids are two principal organic acids in the Malus species [29]. The partitioning of soluble sugars and organic acids in apple fruits is a complex process that is initiated by the transport of photoassimilates (mainly sucrose and sorbitol) to sink tissues via phloem sieve elements. Almost all of the sorbitol and half of the sucrose are converted to fructose, and $80 \%$ of the total carbon flux goes through fructose in apple fruits [30]. Malic acid is mainly synthesized in the cytosol by the reactions catalyzed by phosphoenolpyruvate carboxylase (PEPC; E.C. 4.1.1.31) and malate dehydrogenase (MDH; E.C. 1.1.1.37), whereas it can be degraded via the decarboxylation catalyzed by MDH and the NADP-malic enzyme (ME; E.C. 1.1.1.40) [31]. Additionally, malic acid is mainly stored in vacuoles [32]. Citric acid is produced by the tricarboxylic acid (TCA) cycle in mitochondria. Specifically, it is synthesized by mitochondrial citrate synthase and degraded by aconitase and NAD-dependent isocitrate dehydrogenase (NAD-IDH), which are located in mitochondria and the cytosol, respectively [33,34]. The citric acid concentration in fruit cells is mainly determined by metabolic activities because the uptake of citrate by vacuoles may be limited by the low activity of the citrate transporters in the tonoplast [35].

Proteomic analyses are becoming useful options for the efficient identification of the genes controlling important agronomic traits. In a recent investigation of the genetic diversity associated with the organic acid concentration in apple germplasm, we observed that the mature fruits of two Malus species, M. sargentii and M. niedzwetzkyana, differ regarding their malic and citric acid contents [29]. In the current study, we analyzed the proteomes of the mature fruits of M. sargentii and M. niedzwetzkyana. A total of 31 proteins related to the metabolism of soluble sugars and organic acids as well as $\mathrm{H}^{+}$-ATPase were identified. Our findings will facilitate the characterization of the complex gene network regulating the soluble sugar and organic acid contents in apple fruits. 


\section{Results}

\subsection{Variation in Organic Acid and Soluble Sugar Contents in the Mature Fruits of Two Wild Apple Species}

The organic acid (malic and citric acids) and soluble sugar (sucrose, fructose, glucose, and sorbitol) contents in the mature fruits of two wild apple species, M. sargentii and M. niedzwetzkyana, were determined with a high-performance liquid chromatography (HPLC) system (Figure 1). There were significant variations in the organic acid and soluble sugar contents between the mature fruits of M. sargentii and M. niedzwetzkyana. Regarding the organic acid content, a higher malic acid concentration was detected in M. sargentii mature fruits $(27.20 \mathrm{mg} / \mathrm{g}$ fresh weight $(\mathrm{FW}))$ than in $M$. niedzwetzkyana mature fruits $(3.73 \mathrm{mg} / \mathrm{g} \mathrm{FW})$. Additionally, citric acid was detected only in $M$. sargentii, with an average concentration of $20.22 \mathrm{mg} / \mathrm{g}$ FW. An analysis of the soluble sugars revealed low fructose, glucose, and sucrose concentrations in $M$. sargentii mature fruits, with an average of $26.36 \mathrm{mg} / \mathrm{g}$ FW, $19.53 \mathrm{mg} / \mathrm{g} \mathrm{FW}$, and $5.06 \mathrm{mg} / \mathrm{g} \mathrm{FW}$, respectively. The sorbitol content was greater in M. sargentii mature fruits $(10.44 \mathrm{mg} / \mathrm{g}$ FW) than in M. niedzwetzkyana mature fruits $(7.18 \mathrm{mg} / \mathrm{g}$ FW). Notably, the average fructose and glucose concentrations were more than two times higher than the sucrose and sorbitol concentrations, implying fructose and glucose are the major soluble sugars in $M$. sargentii and M. niedzwetzkyana mature fruits.
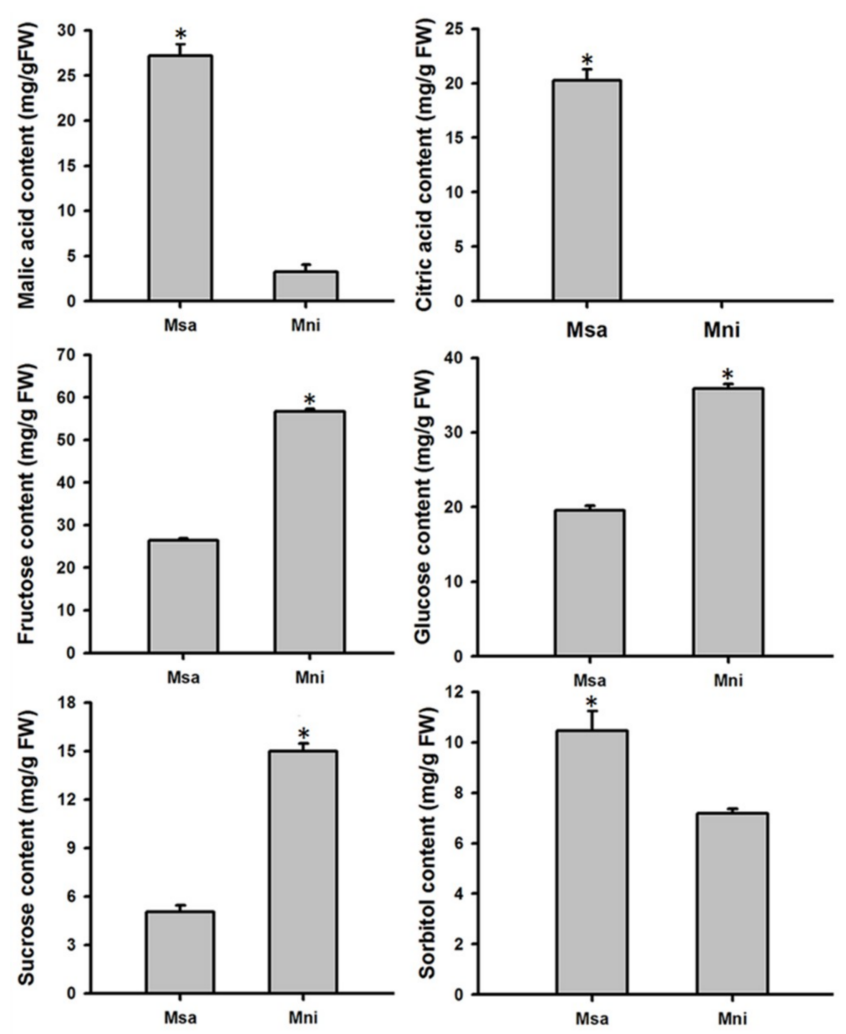

Figure 1. Variation of organic acid and soluble sugar content at maturity of two wide apple fruit. Msa: M. sargentii; Mni: M. niedzwetzkyana. The asterisks $\left({ }^{*}\right)$ indicate significant differences among genotypes $(p<0.01)$. The values represent the average of three biological replicates, and error bars show the SD of the mean. FW-fresh weight.

\subsection{Quality and Coverage of the Apple Fruit Proteome}

In this study, procedures for the enzymatic hydrolysis of proteins, peptide quantification, and MS were completed to identify peptides, quantify proteins, and analyze differentially-expressed proteins. A total of 13,036 unique peptides were identified and 2901 proteins were quantified, with 2088 and 2347 identified in $M$. sargentii and M. niedzwetzkyana mature fruits, respectively (Table 1). Of the quantified 
proteins, 1697 (58.50\%) were identified in both $M$. sargentii and M. niedzwetzkyana mature fruits. Moreover, $72.84 \%$ of the proteins were detected with two or more peptides, indicating the proteins were effectively separated and identified based on label-free shot-gun technology. The identification of proteins was highly reproducible across biological replicates, with $67.15 \%$ of all identifications reproducible in all three biological replicates, whereas $15.33 \%$ and $17.52 \%$ of the identifications were made in only two and one replicate, respectively.

Table 1. Statistics on the protein identification results.

\begin{tabular}{cccccc}
\hline \multirow{2}{*}{$\begin{array}{c}\text { Identification } \\
\text { Results }\end{array}$} & \multirow{2}{*}{$\begin{array}{c}\text { Unique } \\
\text { Peptides }\end{array}$} & \multirow{2}{*}{$\begin{array}{c}\text { Quantified } \\
\text { Proteins }\end{array}$} & Up-Regulated & Down-Regulated & $\begin{array}{c}\text { Significantly } \\
\text { Different } \\
\text { Proteins }\end{array}$ \\
\cline { 4 - 5 } & 13036 & 2901 & 416 & 663 & 1079 \\
\hline
\end{tabular}

Differentially-expressed proteins were defined as those whose abundance differed by more than one fold between the $M$. sargentii and M. niedzwetzkyana mature fruits $(p<0.05)$. A total of 1,079 differentially-expressed proteins were identified, of which 416 and 663 were more and less abundant, respectively, in $M$. sargentii mature fruits than in $M$. niedzwetzkyana mature fruits. Of these 416 and 663 proteins, 175 and 418 were exclusive to the M. sargentii and M. niedzwetzkyana mature fruits, respectively.

\subsection{Verification of the Differentially Expressed Proteins by PRM}

In this study, five candidate proteins were randomly selected and analyzed by LC-PRM/MS to verify the accuracy of the identification of differentially-expressed proteins (Table 2). The PRM results were consistent with the results of the label-free technique for the five analyzed proteins (MDP0000271088, MDP0000152497, MDP0000326249, MDP0000777702, and MDP0000308185), implying that the label-free LC-MS/MS proteomic analysis produced accurate and reliable quantitative data.

Table 2. Quantitative results for five candidate proteins determined using the parallel reaction monitoring (PRM) methods.

\begin{tabular}{cccccccc}
\hline Peptide Sequence & Protein Name & \multicolumn{2}{c}{ Average Content } & PRM Fold & \begin{tabular}{c} 
Label-Free \\
Fold \\
\cline { 3 - 4 } Change
\end{tabular} & $\begin{array}{c}\text { Consistency } \\
\text { between PRM } \\
\text { and Label-Free }\end{array}$ \\
\hline $\begin{array}{c}\text { EYYTNALAAAK } \\
\text { ESLGNFPDLAGAVNK }\end{array}$ & MDP0000271088 & 0.0127 & 0.1152 & 0.1106 & 0.7260 & Yes \\
$\begin{array}{c}\text { FLVSDSFPGNDR } \\
\text { LVPIINPTTR }\end{array}$ & MDP0000152497 & 0.6065 & 0.7086 & 0.8559 & 0.3358 & Yes \\
$\begin{array}{c}\text { INDQAGYSSFR } \\
\text { LANILHANELAR } \\
\text { ANEAALDLVR }\end{array}$ & MDP0000326249 & 0.4397 & 0.0483 & 9.1035 & 2.9726 & Yes \\
$\begin{array}{c}\text { YNEGALPGFDPTK } \\
\text { AFVDSGAQSTISK }\end{array}$ & MDP0000777702 & 0.3039 & $/$ & - & - & Yes \\
$\begin{array}{c}\text { GIAHGVGQSEILGR } \\
\text { LVELGFGR }\end{array}$ & MDP0000308185 & $/$ & 0.2294 & - & - & Yes \\
\hline
\end{tabular}

\subsection{Analysis of Differentially-Expressed Proteins Based on the gene ontology (GO) and KEGG Databases}

The proteins that were differentially expressed between the M. sargentii and M. niedzwetzkyana mature fruits were functionally annotated based on the following three main gene ontology (GO) categories: biological process, cellular component, and molecular function [36,37] (Figure 2, Table S1). The results indicated that the significantly-enriched biological process GO terms were mainly related to nine processes (cellular process, GO:0009987; single-organism process, GO:0044699; metabolic process, GO:0008152; response to stimulus, GO:0050896; biological regulation, GO:0065007; developmental process, GO:0032502; cellular component organization or biogenesis, GO:0071840; localization, GO:0051179; and multicellular organismal process, GO:0032501). The significantly enriched cellular component GO terms were cell part (GO:0044464), cell (GO:0005623), organelle (GO:0043226), membrane 
(GO:0016020), and organelle part (GO:0044422). Finally, within the molecular function category, binding (GO:0005488) and catalytic activity (GO:0003824) were the main enriched GO terms.

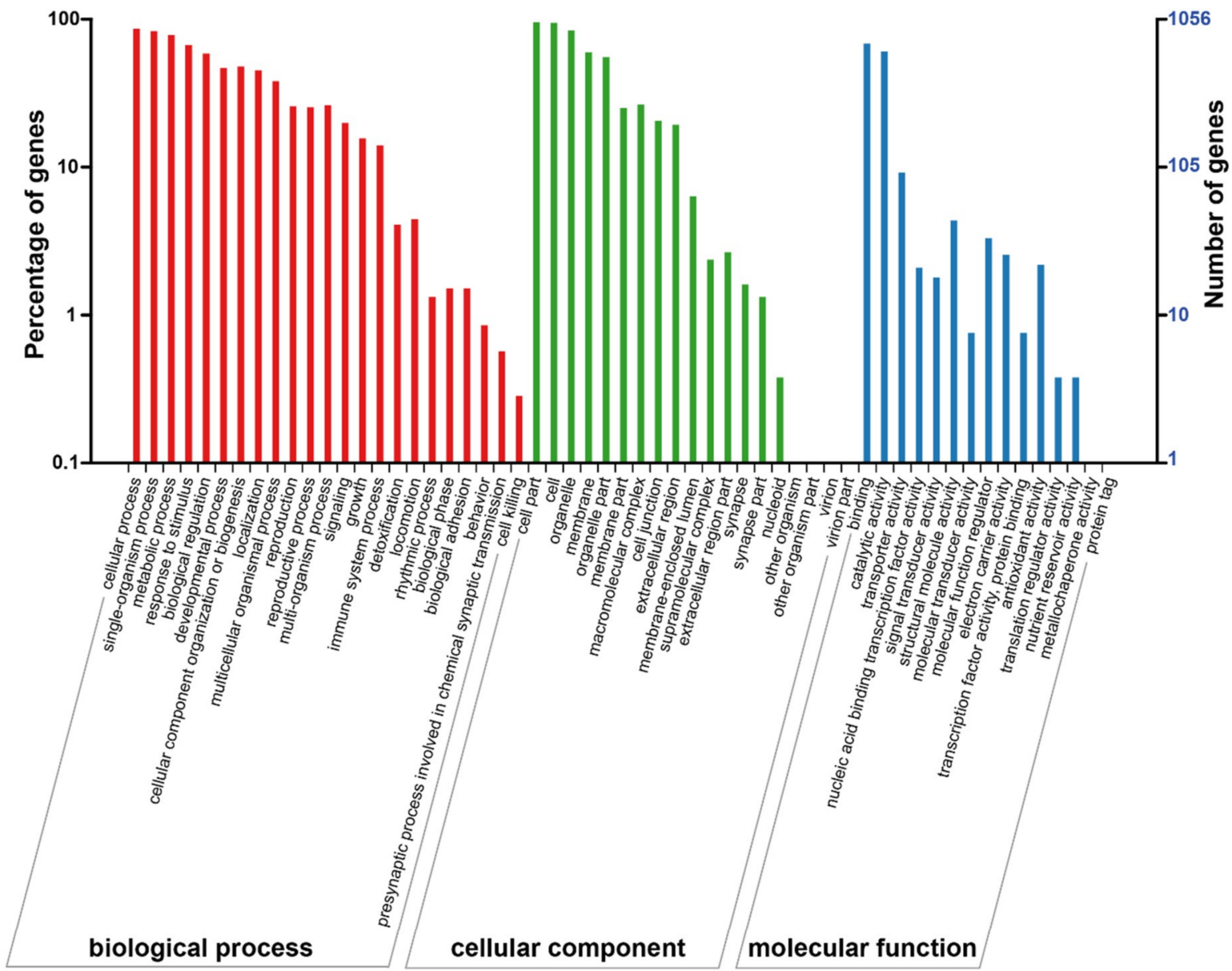

Figure 2. Gene ontology (GO) functional analysis results for the differentially-expressed proteins in mature fruits between $M$. sargentii and M. niedzwetzkyana.

The differentially-expressed proteins were classified into the following five groups based on the functional annotation with the KEGG database: cellular processes, environmental information processing, genetic information processing, metabolism, and organismal systems (Figure 3, Table S2). The KEGG classification results suggested the differentially-expressed proteins were mainly involved in metabolic processes. The metabolic pathways associated with the most differentially-expressed proteins were carbon metabolism (KO01200, Figure S1), biosynthesis of amino acids (KO01230), starch and sucrose metabolism (KO00500, Figure S2), and amino sugar and nucleotide sugar metabolism (KO00520). Carbon, starch, and sucrose metabolism are related to the conversion between primary metabolites, including soluble sugars and organic acids. Thus, through a series of reactions, soluble sugars, and organic acids can be efficiently synthesized and maintained at a certain concentration. 


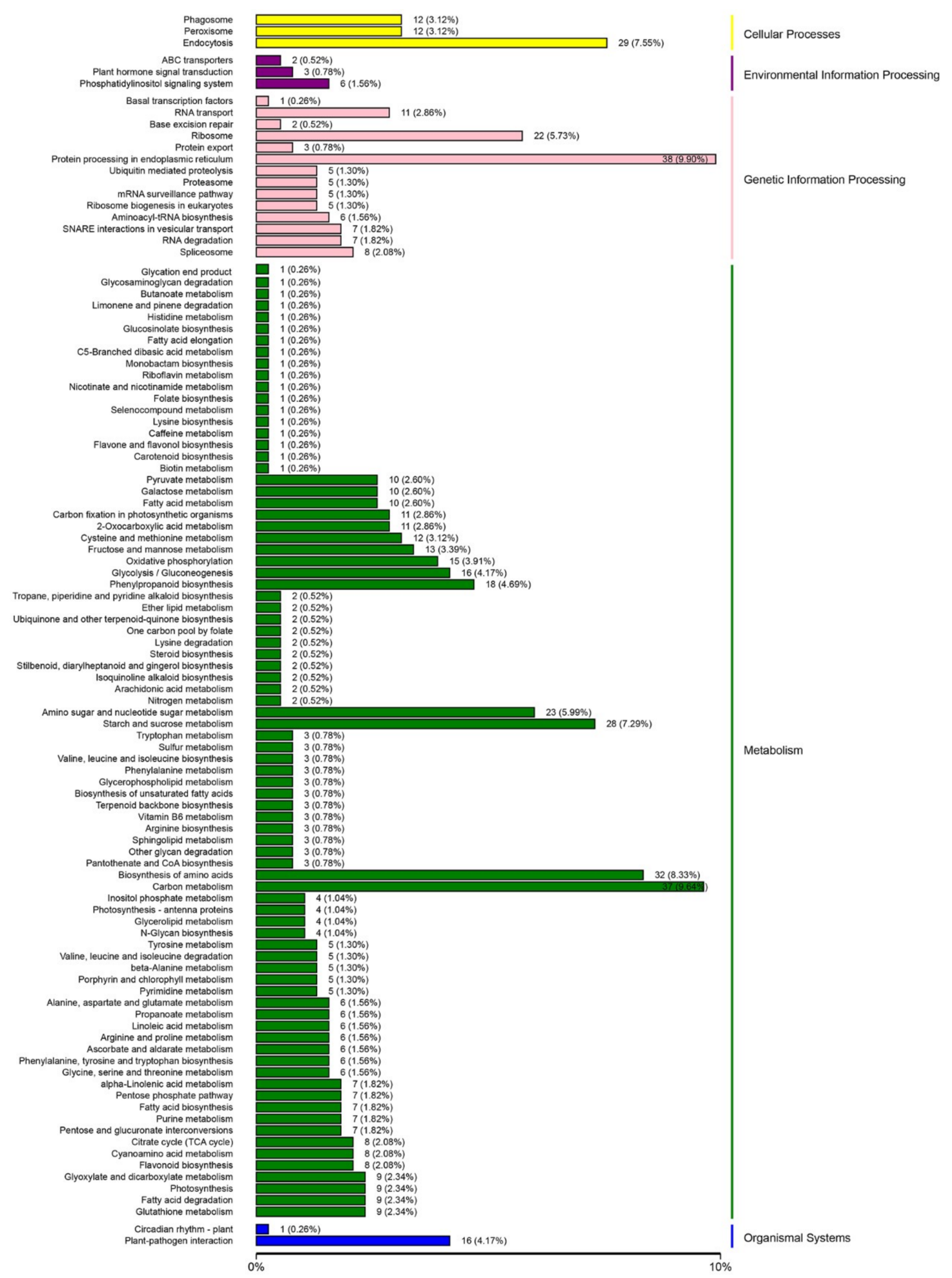

Figure 3. Kyoto Encyclopedia of Genes and Genomes (KEGG) pathways with the differentially-expressed proteins in mature fruits between $M$. sargentii and M. niedzwetzkyana. Each bar is followed by the number of the differentially-expressed proteins and its percentage.

\subsection{Specificity of the Protein Accumulation Related to Soluble Sugar and Organic Acid Metabolism}

The final organic acid and soluble sugar contents of mature fruits depend on their synthesis, degradation, and compartmentalization in subcellular organelles. To explore the mechanisms underlying the metabolism of soluble sugars and organic acids in M. sargentii and M. niedzwetzkyana 
mature fruits, the associated differentially-expressed proteins were identified. A total of 22 differentially-expressed proteins with known roles in the metabolism of soluble sugars and organic acids were identified (Figure 4, Table S3), including six enzymes of the Suc-Suc cycle (previously called 'futile recycles' [30]), five enzymes related to glycolysis, seven enzymes related to pyruvate metabolism, three enzymes of the TCA cycle, and one enzyme involved in the glyoxylate cycle.

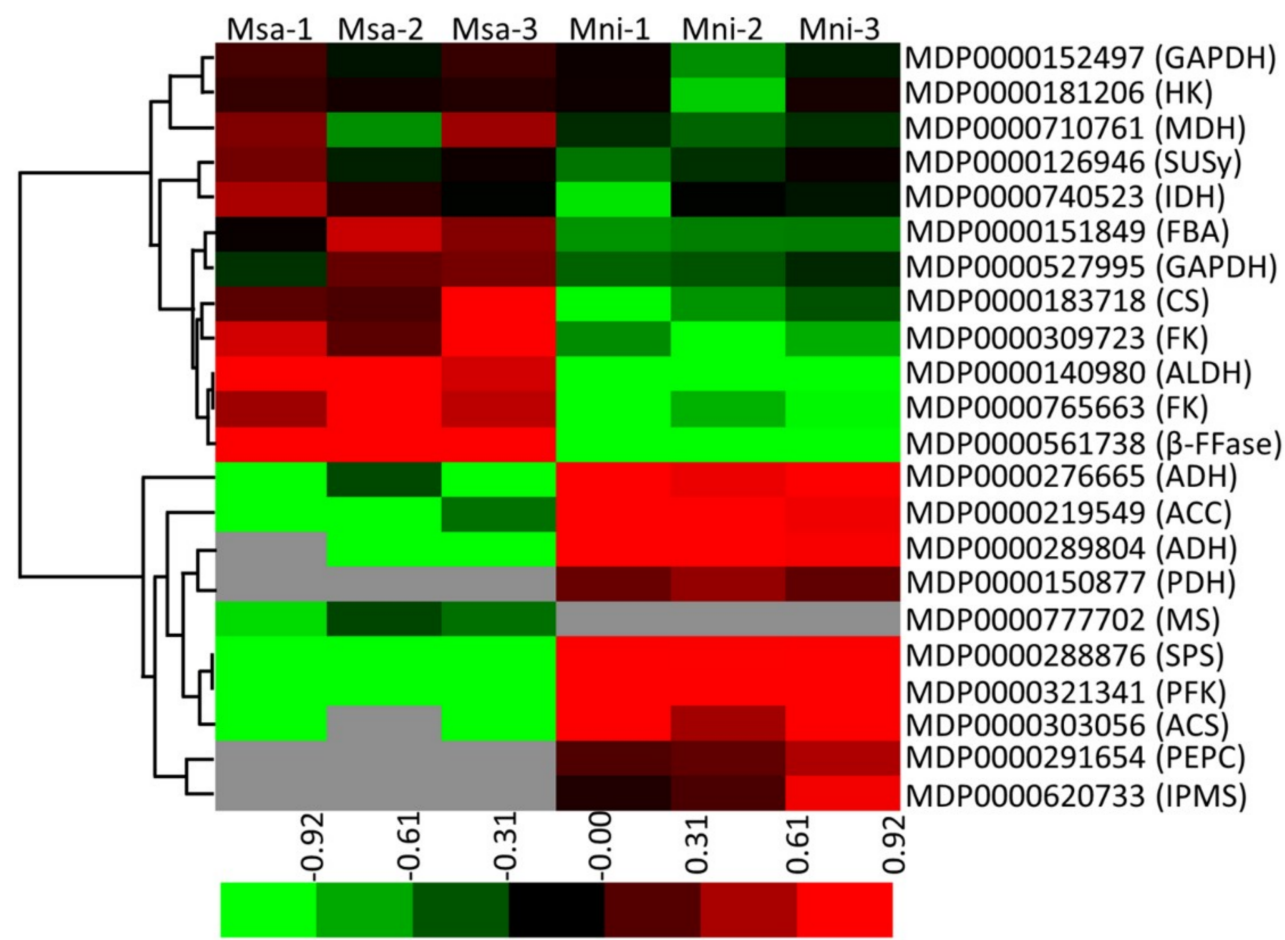

Figure 4. The differentially-expressed proteins involved in soluble sugar and organic acid metabolism in two Malus species mature fruits. The heat map was constructed using Mev software based on relative levels of differentially-expressed proteins, and normalized $\log ^{2}$-transformed values were used to perform hierarchical clustering. Different colors represent differentially-expressed protein levels. MS: malate synthase; $\beta$-FFase: beta-fructofuranosidase; ALDH: aldehyde dehydrogenase; FK: fructokinase; CS: citrate synthase; FBA: fructose-bisphosphate aldolase; IDH: isocitrate dehydrogenase (NAD+); $\mathrm{MDH}$ : malate dehydrogenase; GAPDH: glyceraldehyde-3-phosphate dehydrogenase; SuSy: sucrose synthase; GAPDH: glyceraldehyde-3-phosphate dehydrogenase; HK: hexokinase; SPS: sucrose-phosphate synthase; ADH: alcohol dehydrogenase (NADP+); ACS: acetyl-CoA synthetase; ACC: acetyl-CoA carboxylase carboxyl transferase; PFK: phosphofructokinase; PEPC: phosphoenolpyruvate carboxylase; IPMS: 2-isopropylmalate synthase; PDH: pyruvate dehydrogenase.

Regarding the proteins involved in the Suc-Suc cycle, beta-fructofuranosidase (MDP0000561738), sucrose synthase (MDP0000126946), hexokinase (MDP0000181206), and two fructokinases (MDP0000765663 and MDP0000309723) were significantly more abundant in $M$. sargentii mature fruits than in M. niedzwetzkyana mature fruits. In contrast, the sucrose-phosphate synthase (MDP0000288876) level in M. sargentii mature fruits was approximately two fifths of that in M. niedzwetzkyana mature fruits. Among the proteins related to glycolysis, fructose-bisphosphate aldolase (MDP0000151849) and two glyceraldehyde-3-phosphate dehydrogenases (MDP0000152497 and MDP0000527995) were more abundant in M. sargentii mature fruits than in M. niedzwetzkyana mature fruits, whereas the abundance of phosphofructokinase (MDP0000321341), which is one of the rate-limiting enzymes of glycolysis, was much lower in $M$. sargentii mature fruits than in M. niedzwetzkyana mature fruits. Moreover, a phosphoenolpyruvate carboxylase (MDP0000291654) was identified only in M. niedzwetzkyana mature fruits. This enzyme is important for bypassing the reaction catalyzed by pyruvate kinase during glycolysis to mediate the synthesis of oxaloacetate (OAA) from phosphoenolpyruvate. 
Pyruvate is a major product of glycolysis and is also an important intermediate during the transformation of sugars, organic acids, amino acids, and other compounds in fruits. Pyruvate dehydrogenase (MDP0000150877), which catalyzes the synthesis of acetyl-CoA from pyruvate, was detected only in M. niedzwetzkyana mature fruits. Aldehyde dehydrogenase functions downstream of the pyruvate metabolic pathway by converting acetaldehydes produced from pyruvate metabolism to acetate, which can then be reduced to acetyl-CoA by acetyl-CoA synthetase. The abundance of aldehyde dehydrogenase (MDP0000140980) in M. sargentii mature fruits was 9.25-fold higher than that in M. niedzwetzkyana mature fruits, whereas the acetyl-CoA synthetase (MDP0000303056) level was 41\% lower in M. sargentii mature fruits than in M. niedzwetzkyana mature fruits. Moreover, two enzymes that help degrade acetyl-CoA (acetyl-CoA carboxylase carboxyl transferase (MDP0000219549) and a 2-isopropylmalate synthase (MDP0000620733)) were significantly less abundant (or undetectable) in $M$. sargentii mature fruits than in M. niedzwetzkyana mature fruits.

The TCA cycle is an important pathway involved in the conversion of di- and tri-carboxylates, including malate and citrate. Citrate synthase (CS), NAD-IDH, and NAD-dependent malate dehydrogenase (NAD-MDH) were the three enzymes involved in the TCA cycle that were identified in the present study. The CS (MDP0000183718) level was 4.05-fold higher in M. sargentii mature fruits than in M. niedzwetzkyana mature fruits (Figure 4, Table S3). Similarly, NAD-IDH (MDP0000740523), which degrades isocitrate to generate 2-oxoglutarate, was 2.79-fold more abundant in $M$. sargentii mature fruits than in M. niedzwetzkyana mature fruits. Additionally, NAD-MDH catalyzes the interconversion of OAA and malate, but it favors the synthesis of malate. The NAD-MDH (MDP0000710761) abundance was 2.64-fold higher in M. sargentii mature fruits than in M. niedzwetzkyana mature fruits. Furthermore, a malate synthase (MDP0000777702) associated with the glyoxylate cycle was identified, but only in M. sargentii mature fruits.

\subsection{Identification of Proteins Involved in $\mathrm{H}^{+}$transport}

The $\mathrm{H}^{+}$-ATPases in plants catalyze the synthesis or hydrolysis of ATP coupled with proton translocation, and can be divided into the following three major classes based on structure, localization, and the mechanism underlying their function: F-type (mitochondrial or plastid membrane $\mathrm{F}_{1} \mathrm{~F}_{0}$-ATP synthase), P-type (plasma membrane associated), and V-type (vacuolar or vesicular associated). Three F-type, three P-type, and three V-type $\mathrm{H}^{+}$-ATPases were identified in the current study (Figure 5, Table S3). The abundance of the three F-type $\mathrm{H}^{+}$-ATPases (MDP0000385730, MDP0000545884, and MDP0000448896) was significantly higher in $M$. sargentii mature fruits than in M. niedzwetzkyana mature fruits, whereas the abundance of the three P-type $\mathrm{H}^{+}$-ATPases (MDP0000157578, MDP0000277881, and MDP0000150049) exhibited the opposite pattern. Regarding the three V-type $\mathrm{H}^{+}$-ATPases, the abundance of VHA-d (MDP0000186579) was 2.02-fold higher in M. sargentii mature fruits than in M. niedzwetzkyana mature fruits, whereas VHA-c1 (MDP0000123144) and VHA-B (MDP0000367944) were detected only in $M$. sargentii mature fruits. 


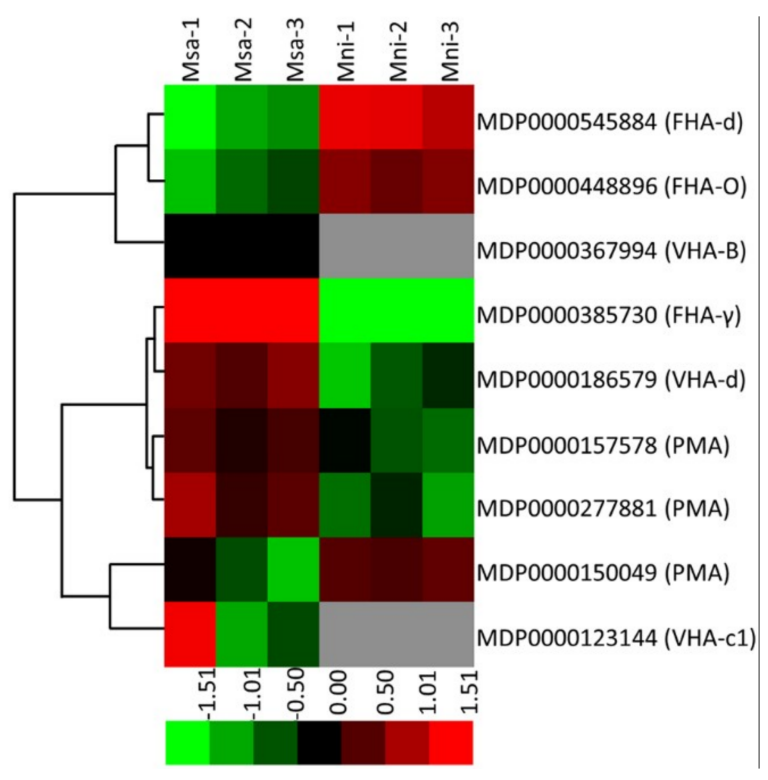

Figure 5. The differentially-expressed proteins involved in the $\mathrm{H}^{+}$transport process in two Malus species mature fruits. The heat map was constructed using Mev software based on relative levels of differentially-expressed proteins, and normalized $\log ^{2}$-transformed values were used to perform hierarchical clustering. Different colors represent differentiallyexpressed protein levels. VHA-c1: V-type $\mathrm{H}^{+}$-transporting ATPase subunit c1; VHA-B: V-type $\mathrm{H}^{+}$-transporting ATPase subunit B; FHA- $\gamma$ : F-type $\mathrm{H}^{+}$-transporting ATPase subunit gamma; FHA-d: F-type $\mathrm{H}^{+}$-transporting ATPase subunit d; FHA-O: F-type $\mathrm{H}^{+}$-transporting ATPase subunit O; VHA-d: V-type $\mathrm{H}^{+}$-transporting ATPase subunit d; PMA: $\mathrm{H}^{+}$-transporting ATPase.

\section{Discussion}

Label-free proteomic techniques based on LC-MS/MS, which is widely used for quantitative analyses of protein expression, overcome the shortcomings of the traditional methods that cannot quantify proteins [19]. In plants, data derived from large-scale proteomic studies helped elucidate stress responses and tolerance [38,39], development [40-42], and metabolic fluxes and functions [30,43,44]. In the current study, a label-free proteomic analysis involving LC-MS/MS was performed to investigate the accumulation of soluble sugars and organic acids in the fruits of two wild apple species. The GO terms enriched among the 1,079 differentially-expressed proteins were mainly related to biological processes and cellular components. Additionally, the enriched KEGG pathways were primarily associated with metabolic processes, including carbon metabolism as well as starch and sucrose metabolism. Moreover, 31 of the differentially-expressed proteins were identified as involved in the metabolism of soluble sugars and organic acids as well as $\mathrm{H}^{+}$transport. The LC-PRM/MS data for five differentially-expressed proteins verified the reliability of the label-free proteomic technique applied in this study.

In the current study, the soluble sugar and organic acid contents in the mature fruits of two Malus species, M. sargentii and M. niedzwetzkyana, were measured by HPLC. The major soluble sugars were identified as fructose and glucose, whereas malic and citric acids were detected as the two predominant organic acids, which is consistent with the findings of previous studies [2,29]. Soluble sugars, especially sucrose, glucose, and fructose, are responsible for the sweetness of fruits, whereas organic acids, such as malic and citric acids, determine fruit acidity. A moderate concentration of organic acids can increase the palatability of fruits, but low or high concentrations can decrease fruit quality $[45,46]$. In developing fruits, changes to the sugar and organic acid contents over time are due to the synthesis, degradation, and transport of these compounds. In the current study, 22 differentially-expressed proteins related to the Suc-Suc and TCA cycles were identified (Figure 6, Table S3). Sucrose synthase catalyzes the reversible conversion of sucrose to fructose and uridine diphosphate glucose. The resulting fructose 
can be phosphorylated by fructokinase to generate fructose-6-phoshate. Additionally, glucose can be phosphorylated by hexokinase to produce glucose-6-phoshate [47]. Thus, fructokinase and hexokinase play crucial roles in sugar metabolism and homeostasis. In our study, these three enzymes were more abundant in M. sargentii mature fruits than in M. niedzwetzkyana mature fruits, which may explain the high fructose and glucose contents in M. niedzwetzkyana mature fruits (Figure 1). Sucrose phosphate synthase is believed to be the key enzyme for controlling sucrose biosynthesis. It catalyzes the reaction in the sucrose synthesis pathway that produces sucrose-6-phosphate from fructose-6-phosphate and uridine diphosphate glucose (Figure 6). We detected a greater abundance of sucrose phosphate synthase (MDP0000288876) in M. niedzwetzkyana mature fruits than in M. sargentii mature fruits, which is consistent with the low sucrose content of $M$. sargentii mature fruits.

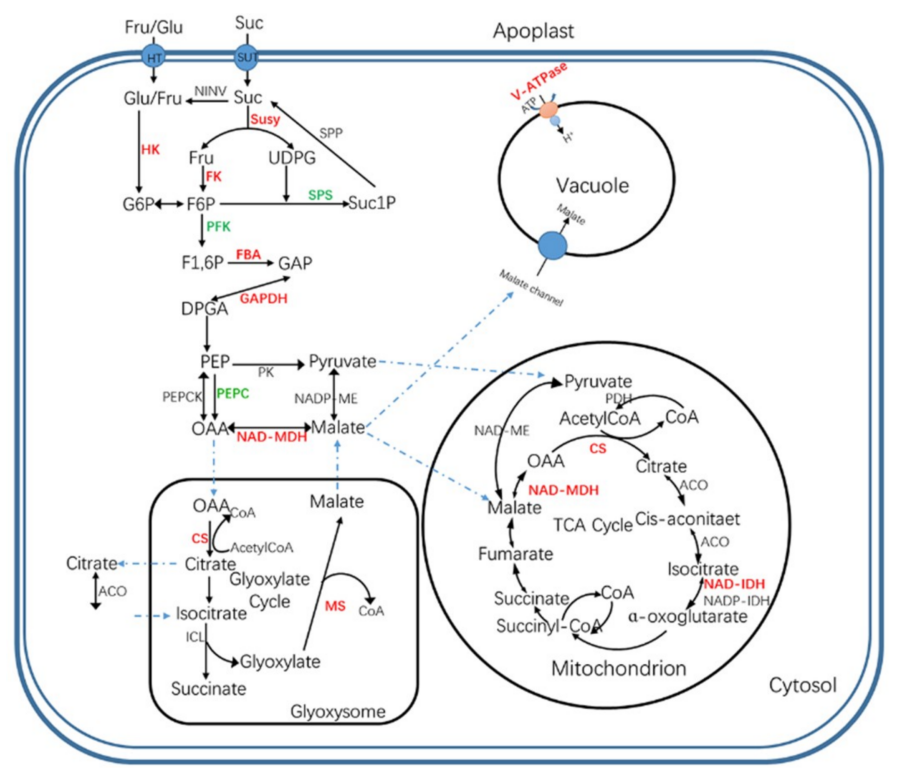

Figure 6. Metabolic network of soluble sugar and organic acid in apple fruits between M. sargentii and M. niedzwetzkyana. The red and green colors represent the proteins with up- and down-regulation in mature apple fruits in M. sargentii compared with that in M. niedzwetzkyana, respectively. For soluble sugar and organic acid metabolism: HK-hexokinase; FK-fructokinase; SUSY-sucrose synthase; SPS—sucrose-phosphate synthase; PFK-phosphofructokinase; FBA-fructose-bisphosphate aldolase; GAPDH-glyceraldehyde-3-phosphate dehydrogenase; PEPC - phosphoenolpyruvate carboxylase; NAD-MDH-NAD-malate dehydrogenase; CS — citrate synthase; MS - malate synthase; NAD-IDH-NAD-isocitrate dehydrogenase; Glu-glucose; Fru-fructose; Suc - sucrose; F6P-fructose-6-phosphate; G6P-glucose-6-phosphate; F1,6P-Fructose 1,6 diphosphate; GAP-glyceraldehyde 3-phosphate; DPGA-1,3-diphosphoglycerate; $\mathrm{PEP}$ - phosphoenolpyruvate; OAA—oxaloacetate.

Fruit acidity is mainly due to the presence of malic and citric acids, which accumulate in fruit cells because of several interlinked processes that appear to be mainly under the control of genetic factors [32]. In fruit cells, malic acid is primarily synthesized in the cytosol by NAD-MDH [48], which mainly catalyzes the reversible conversion of OAA to malate [31,49]. Yao et al. revealed that the overexpression of apple $M d M D H$, which encodes NAD-MDH, leads to increased malate levels, suggesting its direct involvement in malate synthesis. The overexpression of $M d M D H$ also results in the up-regulated expression of several malate-related genes, implying MdMDH also indirectly affects malate accumulation [49]. In the present study, the NAD-MDH (MDP0000710761) content was higher in $M$. sargentii mature fruits than in M. niedzwetzkyana mature fruits. Additionally, the glyoxylate cycle may influence malate accumulation in young grape berries and ripening banana fruits [50,51]. In our study, a malate synthase (MDP0000777702), which contributes to malate synthesis in the glyoxylate 
cycle, was detected only in $M$. sargentii mature fruits. These results suggest that the genes related to malate synthesis are crucial for the accumulation of malic acid in fruit cells. Citric acid is produced via the TCA cycle in mitochondria, with mitochondrial citrate synthase as the crucial enzyme controlling citrate synthesis $[33,34]$. Furthermore, citrate accumulation is mainly controlled by metabolic activities, not the uptake of citrate by vacuoles [35]. In our study, the CS (MDP0000183718) abundance was considerably higher in M. sargentii mature fruits than in M. niedzwetzkyana mature fruits, indicating that CS likely controls the citric acid content in $M$. sargentii mature fruits.

Vacuoles are a major repository for organic acids, as evidenced by the fact that organic acid concentrations in the vacuole exceed the corresponding concentrations in the cytosol by several-fold [32,52]. In the cytosol, at neutral or slightly alkaline $\mathrm{pH}$, almost all of the malate and citrate are in the form of dianions and trianions, respectively. These forms can be transported into vacuoles, wherein the dominant species are the protonated forms because of the acidic nature of vacuoles. After the dianions and trianions cross the tonoplast to reach the acidic vacuole, they are immediately protonated, which maintains their electrochemical potential gradient and enables their continuous transport into the vacuole (i.e., acid trap mechanism) [32,53]. The trapping efficiency depends on two factors, namely the vacuolar $\mathrm{pH}$ and the electric potential gradient across the tonoplast, which are generated by the protons pumped into the vacuole. The V-type $\mathrm{H}^{+}$-ATPases are one of the major proton pumps in fruit cell vacuoles [32]. They can hydrolyze the high-energy phosphate bond of ATP and promote the transport of protons into vacuoles. Several studies suggested that the difference in the organic acid content between fruit species and between different cultivars of the same fruit species may be linked to the diversity in their proton pumps [10,54,55]. In the present study, three V-type $\mathrm{H}^{+}$-ATPases were more abundant in $M$. sargentii mature fruits than in M. niedzwetzkyana mature fruits. Thus, we speculate that the higher malic and citric acid contents in $M$. sargentii mature fruits than in $M$. niedzwetzkyana mature fruits are likely due to the greater ability of $M$. sargentii mature fruits to synthesize malic and citric acids as well as the higher trapping efficiency of their vacuoles for malate and citrate.

\section{Materials and Methods}

\subsection{Plant Materials}

The two Malus species used in this study, M. sargentii and M. niedzwetzkyana, were grown at the Horticultural Experimental Station of Northwest A\&F University, Yangling, Shaanxi province, China, with standard horticultural practices and pest and disease control measures. In 2016, mature fruits were collected at 90 days after full bloom. The maturity of the collected fruits was confirmed based on their weight, seed color, and the results of a starch iodine test. Fruits with a uniform size and color and free of visible injuries or blemishes were selected for the subsequent experiments, which were completed with at least three biological replicates. Five fruits sampled from the same tree constituted one biological replicate. Pooled fruit samples were peeled, sliced into pieces, transferred to a pre-chilled centrifuge tube, flash-frozen in liquid nitrogen, and stored at $-80{ }^{\circ} \mathrm{C}$ until analyzed.

\subsection{Determination of Soluble Sugar and Organic Acid Contents}

The soluble sugar and organic acid contents in apple fruits were measured with an HPLC system as previously described [2]. Briefly, for each replicate, approximately $5 \mathrm{~g}$ of fruit sample were added to liquid nitrogen in a mortar and ground to a powder with a pestle. Next, $1 \mathrm{~g}$ of ground powder was dissolved in $5 \mathrm{~mL}$ ddH ${ }_{2} \mathrm{O}$ from the Milli-Q Element water purification system (Millipore, Bedford, MA, USA). The mixture was incubated for $30 \mathrm{~min}$ in a water bath set at $37^{\circ} \mathrm{C}$ prior to an ultrasonic extraction at room temperature for $15 \mathrm{~min}$. The resulting solution was centrifuged at $5000 \times g$ for $15 \mathrm{~min}$ at $4{ }^{\circ} \mathrm{C}$. The supernatant was passed through a $0.22 \mu \mathrm{m}$ Sep-Pak filter (ANPEL, Shanghai, China) and then analyzed with the Agilent 1260 Infinity HPLC system (Milford, MA, USA) to measure the soluble sugar and organic acid contents. 
To detect the organic acids, the HPLC system was coupled to a diode array detector set at $210 \mathrm{~nm}$. The chromatographic separation was conducted on an Athena C18 column $(4.6 \times 250 \mathrm{~mm}, 5 \mu \mathrm{m})$. Specifically, the column temperature was maintained at $40{ }^{\circ} \mathrm{C}$, the mobile phase was $0.02 \mathrm{M} \mathrm{KH}_{2} \mathrm{PO}_{4}$ solution ( $\mathrm{pH}$ 2.4), the injection volume was $20.0 \mu \mathrm{L}$, and the flow rate was $0.8 \mathrm{~mL} / \mathrm{min}$.

The soluble sugars were detected with the HPLC system coupled to a refractive index detector with the reference cell maintained at $90^{\circ} \mathrm{C}$. The chromatographic separation was conducted with a Transgenomic COREGET-87C column $(7.8 \mathrm{~mm} \times 300 \mathrm{~mm}, 10 \mu \mathrm{m})$ and a Transgenomic CARB Sep Coregel $87 \mathrm{C}$ guard column cartridge. The mobile phase was $\mathrm{ddH}_{2} \mathrm{O}$ and the flow rate was $0.5 \mathrm{~mL} / \mathrm{min}$. The soluble sugar and organic acid standards used during the HPLC analyses were purchased from Sigma (St. Louis, MO, USA) and dissolved in deionized water.

\subsection{Protein Extraction, Enzymatic Hydrolysis, and Peptide Quantification}

Fruit samples were frozen in liquid nitrogen and ground with a mortar and pestle. The powder was resuspended in five volumes of TCA/acetone (1:9) and vortexed. The mixture was incubated at $-20{ }^{\circ} \mathrm{C}$ for $4 \mathrm{~h}$ and then centrifuged at $6000 \times g$ for $40 \mathrm{~min}$ at $4{ }^{\circ} \mathrm{C}$. The supernatant was discarded and the pellet was washed three times with pre-cooled acetone. The precipitate was air-dried. Thirty volumes of SDS with DTT (SDT) lysis buffer (4\% SDS, $100 \mathrm{mM}$ dithiothreitol (DTT), and $150 \mathrm{mM}$ Tris-HCl, pH 8.0) was added to 20-30 mg dried sample and the resulting mixture was boiled for $5 \mathrm{~min}$. The lysate was sonicated and then boiled for $15 \mathrm{~min}$. After centrifugation at $14,000 \times \mathrm{g}$ for $40 \mathrm{~min}$, the supernatant was passed through a $0.22 \mu \mathrm{m}$ filter and stored at $-80^{\circ} \mathrm{C}$ until analyzed.

The samples were digested with a tryptic solution according to a modified version of an established filter-aided sample preparation protocol [56]. All of the required chemicals were purchased from Sigma, unless otherwise stated. For each sample, $200 \mu$ g protein were mixed with $30 \mu \mathrm{L}$ SDT buffer. The DTT and other low-molecular-weight components were removed with UA buffer (8 $\mathrm{M}$ urea and $150 \mathrm{mM}$ Tris- $\mathrm{HCl}, \mathrm{pH}$ 8.0) and repeated ultrafiltration. Next, $100 \mu \mathrm{L}$ iodoacetamide (100 mM in UA buffer) were added to block reduced cysteine residues and the samples were incubated for $30 \mathrm{~min}$ in darkness. The filters were washed three times with $100 \mu \mathrm{L}$ UA buffer and then twice with $100 \mu \mathrm{L}$ $25 \mathrm{mM} \mathrm{NH}_{4} \mathrm{HCO}_{3}$ buffer. Finally, the protein suspensions were digested with $4 \mu \mathrm{g}$ trypsin (Promega) in $40 \mu \mathrm{L} 25 \mathrm{mM} \mathrm{NH}_{4} \mathrm{HCO}_{3}$ buffer overnight at $37^{\circ} \mathrm{C}$, and the resulting peptides were collected as a filtrate. The peptides of each sample were desalted with Empore ${ }^{\mathrm{TM}}$ SPE Cartridges (C18; standard density, $7 \mathrm{~mm}$ bed I.D., and $3 \mathrm{~mL}$ volume; Sigma) and then concentrated by vacuum centrifugation and reconstituted in $40 \mu \mathrm{L} 0.1 \%$ (v/v) formic acid.

The LC-MS/MS analysis (120 min) was performed with the EASY-nLC system (Thermo Fisher Scientific) coupled to the $Q$ Exactive mass spectrometer (Thermo Fisher Scientific), which was operated in the positive ion mode. The MS data were acquired with a data-dependent top-10 method that selected the most abundant precursor ions from the survey scan $(300-1800 \mathrm{~m} / \mathrm{z})$ for HCD fragmentation. The automatic gain control target was set to $3 \mathrm{e}^{6}$ and the maximum injection time was set to $10 \mathrm{~ms}$. The dynamic exclusion duration was $40.0 \mathrm{~s}$. Survey scans were acquired at a resolution of 70,000 at $\mathrm{m} / \mathrm{z}$ 200. The resolution for the HCD spectra was set to $17,500 \mathrm{at} \mathrm{m} / \mathrm{z} 200$ and the isolation width was $\mathrm{m} / \mathrm{z}$ 2. The normalized collision energy was $30 \mathrm{eV}$ and the underfill ratio (i.e., the minimum percentage of the target value likely to be reached at the maximum fill time) was defined as $0.1 \%$.

\subsection{Data Analysis}

The original raw LC-MS/MS data were analyzed with the MaxQuant software (version 5.3.17) to screen databases [57]. The main library search parameters are listed in Table 3. 
Table 3. The MaxQuant search library parameter settings.

\begin{tabular}{cc}
\hline Item & Value \\
\hline Enzyme & Trypsin \\
Max missed cleavages & 2 \\
Max missed cleavages & 2 \\
Main search & $6 \mathrm{ppm}$ \\
First search & $20 \mathrm{ppm}$ \\
MS/MS tolerance & $20 \mathrm{ppm}$ \\
Fixed modifications & Carbamidomethyl (C) \\
Variable modifications & $\leq 0.01$ \\
Peptide FDR & $\leq 0.01$ \\
Protein FDR & 2 min \\
Time window (match between runs) & Oxidation (M), acetyl (protein N-term) \\
Protein quantification & Razor and unique peptides were used for protein quantification. \\
\hline
\end{tabular}

\subsection{Bioinformatic Analysis}

The differentially-expressed proteins in the mature fruits of two wild apple species underwent a bioinformatic analysis. The Blast2GO program (http://geneontology.org/) was used to functionally annotate the differentially-expressed proteins. Additionally, the identified proteins were classified and grouped based on the KEGG database (http://www.genome.jp/kegg/). The significance of each identified enriched pathway and GO term were determined with Fisher's exact test, and the target proteins were analyzed based on the GO terms and KEGG pathways [37,58].

\subsection{PRM Verification}

The LC-PRM/MS analysis was conducted with an HPLC liquid phase system Easy-nLC1200 (Thermo Fisher Scientific, Waltham, USA) as previously described with minor modifications [36]. The relevant liquid phase gradient was as follows: $0-2 \mathrm{~min}$, with a linear gradient of B liquid from $5 \%-10 \%$; $2-45 \mathrm{~min}$, with a linear gradient of B liquid from $10 \%-30 \% ; 45-55 \mathrm{~min}$, with a linear gradient of B liquid from 30\%-100\%; 55-60 min, with B liquid maintained at 100\%. The peptides were chromatographed and analyzed using a Q-Exactive HF Mass Spectrometer (Thermo Scientific). Analysis duration: $60 \mathrm{~min}$. Detection method: positive ion. Parent ion scanning range: $300-1800 \mathrm{~m} / \mathrm{z}$. The mass-to-charge ratio of peptide and polypeptide fragments was collected as follows: 20 fragment maps (MS2 scan); mass spectrometry resolution: 30,000 (@ m/z 200); AGC target: $3 \mathrm{e}^{6}$; maximum IT: 120 ms; MS2 activation type: HCD; isolation; normalized collision energy: 27.

Supplementary Materials: The following are available online at http://www.mdpi.com/2223-7747/8/11/488/s1. Figure S1: KEGG map of carbon metabolism pathway based on the differentially-expressed proteins; Figure S2: KEGG map of starch and sucrose metabolism pathway based on the differentially-expressed proteins; Table S1: GO (gene ontology) functional analysis results for the differentially-expressed proteins in mature fruits between M. sargentii and M. niedzwetzkyana; Table S2: KEGG (Kyoto Encyclopedia of Genes and Genomes) pathways with the differentially-expressed proteins in mature fruits between $M$. sargentii and M. niedzwetzkyana; Table S3: the potential key proteins involved in organic acid and soluble sugars metabolism in two Malus species.

Data Archiving Statement: The raw data is currently being prepared for submitting to Proteome Xchange (http://www.proteomexchange.org/).

Author Contributions: B.M., Y.Y., and F.M. conceived and designed the experiments. B.M. and Y.Y. and performed the experiments. Y.Y., C.L., M.L., and Y.D. analyzed the data. B.M. and Y.Y. wrote the manuscript. M.L. and F.M. revised the manuscript. All authors read and approved the final manuscript.

Funding: This work was supported by the National Natural Science Foundation of China (Grant Number 31701875), and China Postdoctoral Science Foundation (Grant Numbers 2017M613225).

Acknowledgments: We thank Liwen Bianji, Edanz Editing China (www.liwenbianji.cn/ac) for editing the English text of a draft of this manuscript and Shanghai Applied Protein Technology Co. Ltd. for the help with Label-free sequencing.

Conflicts of Interest: None of the authors has any relevant conflicts of interest to declare. 


\section{References}

1. Borsani, J.; Budde, C.O.; Porrini, L.; Lauxmann, M.A.; Lombardo, V.A.; Murray, R.; Andreo, C.S.; Drincovich, M.F.; Lara, M.V. Carbon metabolism of peach fruit after harvest: Changes in enzymes involved in organic acid and sugar level modifications. J. Exp. Bot. 2009, 60, 1823-1837. [CrossRef] [PubMed]

2. Ma, B.; Chen, J.; Zheng, H.; Fang, T.; Ogutu, C.; Li, S.; Han, Y.; Wu, B. Comparative assessment of sugar and malic acid composition in cultivated and wild apples. Food Chem. 2015, 172, 86-91. [CrossRef] [PubMed]

3. Ruan, Y.L. Sucrose metabolism: Gateway to diverse carbon use and sugar signaling. Annu. Rev. Plant Biol. 2014, 65, 33-67. [CrossRef] [PubMed]

4. Gottwald, J.R.; Krysan, P.J.; Young, J.C.; Evert, R.F.; Sussman, M.R. Genetic evidence for the in planta role of phloem-specific plasma membrane sucrose transporters. Proc. Natl. Acad. Sci. USA 2000, 97, 13979-13984. [CrossRef] [PubMed]

5. Zhen, Q.; Fang, T.; Peng, Q.; Liao, L.; Zhao, L.; Owiti, A.; Han, Y. Developing gene-tagged molecular markers for evaluation of genetic association of apple SWEET genes with fruit sugar accumulation. Hortic. Res. 2018, 5, 14. [CrossRef] [PubMed]

6. Diakou, P.; Svanella, L.; Raymond, P.; Gaudillère, J.P.; Moing, A. Phosphoenolpyruvate carboxylase during grape berry development: Protein level, enzyme activity and regulation. Aust. J. Plant. Physiol. 2000, 27, 221-229. [CrossRef]

7. Mahmood, T.; Anwar, F.; Abbas, M.; Boyce, M.C.; Saari, N. Compositional variation in sugars and organic acids at different maturity stages in selected small fruits from Pakistan. Int. J. Mol. Sci. 2012, 13, 1380-1392. [CrossRef] [PubMed]

8. Chen, F.X.; Liu, X.H.; Chen, L.S. Developmental changes in pulp organic acid concentration and activities of acid-metabolising enzymes during the fruit development of two loquat (Eriobotrya japonica Lindl.) cultivars differing in fruit acidity. Food Chem. 2009, 114, 657-664. [CrossRef]

9. Wu, J.; Gao, H.; Zhao, L.; Liao, X.; Chen, F.; Wang, Z.; Hu, X. Chemical compositional characterization of some apple cultivars. Food Chem. 2007, 103, 88-93. [CrossRef]

10. Lu, X.P.; Liu, Y.Z.; Zhou, G.F.; Wei, Q.J.; Hu, H.J.; Peng, S.A. Identification of organic acid-related genes and their expression profiles in two pear (Pyrus pyrofolia) cultivars with difference in predominant acid type at fruit ripening stage. Sci. Hortic. 2011, 129, 680-687. [CrossRef]

11. Scherer, R.; Rybka, A.C.P.; Ballus, C.A.; Meinhart, A.D.; Filho, J.T.; Godoy, H.T. Validation of a HPLC method for simultaneous determination of main organic acids in fruits and juices. Food Chem. 2012, 135, 150-154. [CrossRef]

12. Chandramouli, K.; Qian, P.Y. Proteomics: Challenges, Techniques and Possibilities to Overcome Biological Sample Complexity. Hum. Genom. Proteom. 2009, 2009, 239204. [CrossRef] [PubMed]

13. Gallego, M.; Mora, L.; Aristoy, M.C.; Toldrá, F. Optimisation of a simple and reliable label-free methodology for the relative quantitation of raw pork meat proteins. Food Chem. 2015, 182, 74-80. [CrossRef] [PubMed]

14. Aebersold, R.; Mann, M. Mass spectrometry-based proteomics. Nature 2003, 422, 198-207. [CrossRef] [PubMed]

15. Ong, S.E.; Blagoev, B.; Kratchmarova, I.; Kristensen, D.B.; Steen, H.; Pandey, A.; Mann, M. Stable isotope labeling by amino acids in cell culture, SILAC, as a simple and accurate approach to expression proteomics. Mol. Cell. Proteom. 2002, 1, 376-386. [CrossRef] [PubMed]

16. Washburn, M.P.; Ulaszek, R.; Deciu, C.; Schieltz, D.M.; Yates, J.R. Analysis of quantitative proteomic data generated via multidimensional protein identification technology. Anal. Chem. 2002, 74, 1650-1657. [CrossRef] [PubMed]

17. Chelius, D.; Bondarenko, P.V. Quantitative profiling of proteins in complex mixtures using liquid chromatography and mass spectrometry. J. Proteome Res. 2002, 1, 317-323. [CrossRef] [PubMed]

18. Quadroni, M.; Ducret, A.; Stöcklin, R. Quantify this! Report on a round table discussion on quantitative mass spectrometry in proteomics. Proteomics 2004, 4, 2211-2215. [CrossRef] [PubMed]

19. Neilson, K.A.; Ali, N.A.; Muralidharan, S.; Mirzaei, M.; Mariani, M.; Assadourian, G.; Lee, A.; van Sluyter, S.C.; Haynes, P.A. Less label, more free: Approaches in label-free quantitative mass spectrometry. Proteomics 2011, 11, 535-553. [CrossRef] [PubMed] 
20. Peterson, A.C.; Russell, J.D.; Bailey, D.J.; Westphall, M.S.; Coon, J.J. Parallel reaction monitoring for high resolution and high mass accuracy quantitative, targeted proteomics. Mol. Cell. Proteom. 2012, 11, 1475-1488. [CrossRef] [PubMed]

21. Rauniyar, N. Parallel Reaction Monitoring: A Targeted Experiment Performed Using High Resolution and High Mass Accuracy Mass Spectrometry. Int. J. Mol. Sci. 2015, 16, 28566-28581. [CrossRef] [PubMed]

22. Aebersold, R.; Burlingame, A.L.; Bradshaw, R.A. Western blots versus selected reaction monitoring assays: Time to turn the tables? Mol. Cell. Proteom. 2013, 12, 2381-2382. [CrossRef] [PubMed]

23. Daccord, N.; Celton, J.M.; Linsmith, G.; Becker, C.; Choisne, N.; Schijlen, E.; van de Geest, H.; Bianco, L.; Micheletti, D.; Velasco, R.; et al. High-quality de novo assembly of the apple genome and methylome dynamics of early fruit development. Nat. Genet. 2017, 49, 1099-1106. [CrossRef] [PubMed]

24. Velasco, R.; Zharkikh, A.; Affourtit, J.; Dhingra, A.; Cestaro, A.; Kalyanaraman, A.; Fontana, P.; Bhatnagar, S.K.; Troggio, M.; Pruss, D.; et al. The genome of the domesticated apple (Malus $\times$ domestica Borkh.). Nat. Genet. 2010, 42, 833-839. [CrossRef] [PubMed]

25. Liu, Y.L.; Zhang, X.J.; Zhao, Z.Y. Effects of fruit bagging on anthocyanins, sugars, organic acids, and color properties of 'Granny Smith' and 'Golden Delicious' during fruit maturation. Eur. Food Res. Technol. 2013, 236, 329-339. [CrossRef]

26. Hecke, K.; Herbinger, K.; Veberic, R.; Trobec, M.; Toplak, H.; Stampar, F.; Keppel, H.; Grill, D. Sugar-, acidand phenol contents in apple cultivars from organic and integrated fruit cultivation. Eur. J. Clin. Nutr. 2006, 60, 1136-1140. [CrossRef] [PubMed]

27. Petkovsek, M.M.; Stampar, F.; Veberic, R. Parameters of inner quality of the apple scab resistant and susceptible apple cultivars (Malus domestica Borkh.). Sci. Hortic. 2007, 114, 37-44. [CrossRef]

28. Zhang, Y.; Li, P.; Cheng, L. Developmental changes of carbohydrates, organic acids, amino acids, and phenolic compounds in 'Honeycrisp' apple flesh. Food Chem. 2010, 123, 1013-1018. [CrossRef]

29. Ma, B.Q.; Yuan, Y.Y.; Gao, M.; Li, C.Y.; Ogutu, C.; Li, M.J.; Ma, F.W. Determination of Predominant Organic Acid Components in Malus Species: Correlation with Apple Domestication. Metabolites 2018, 8, 74. [CrossRef] [PubMed]

30. Li, M.; Li, D.; Feng, F.; Zhang, S.; Ma, F.; Cheng, L. Proteomic analysis reveals dynamic regulation of fruit development and sugar and acid accumulation in apple. J. Exp. Bot. 2016, 67, 5145-5157. [CrossRef] [PubMed]

31. Sweetman, C.; Deluc, L.G.; Cramer, G.R.; Ford, C.M.; Soole, K.L. Regulation of malate metabolism in grape berry and other developing fruits. Phytochemistry 2009, 70, 1329-1344. [CrossRef] [PubMed]

32. Etienne, A.; Génard, M.; Lobit, P.; Mbeguié-A-Mbéguié, D.; Bugaud, C. What controls fleshy fruit acidity? A review of malate and citrate accumulation in fruit cells. J. Exp. Bot. 2013, 64, 145-169. [CrossRef] [PubMed]

33. Katz, E.; Boo, K.H.; Kim, H.Y.; Eigenheer, R.A.; Phinney, B.S.; Shulaev, V.; Negre-Zakharov, F.; Sadka, A.; Blumwald, E. Label-free shotgun proteomics and metabolite analysis reveal a significant metabolic shift during citrus fruit development. J. Exp. Bot. 2011, 62, 5367-5384. [CrossRef] [PubMed]

34. Sadka, A.; Dahan, E.; Or, E.; Roose, M.L.; Marsh, K.B.; Cohen, L. Comparative analysis of mitochondrial citrate synthase gene structure, transcript level and enzymatic activity in acidless and acid-containing Citrus varieties. Funct. Plant. Biol. 2001, 28, 383-390. [CrossRef]

35. Hafke, J.B.; Hafke, Y.; Smith, J.A.; Lüttge, U.; Thiel, G. Vacuolar malate uptake is mediated by an anion-selective inward rectifier. Plant. J. 2003, 35, 116-128. [CrossRef] [PubMed]

36. He, Q.; Fang, X.; Zhu, T.; Han, S.; Zhu, H.; Li, S. Differential Proteomics Based on TMT and PRM Reveal the Resistance Response of Bambusa pervariabilis $\times$ Dendrocalamopisis grandis Induced by AP-Toxin. Metabolites 2019, 9, 166. [CrossRef] [PubMed]

37. Ashburner, M.; Ball, C.A.; Blake, J.A.; Botstein, D.; Butler, H.; Cherry, J.M.; Davis, A.P.; Dolinski, K.; Dwight, S.S.; Eppig, J.T.; et al. Gene ontology: Tool for the unification of biology. The Gene Ontology Consortium. Nat. Genet. 2000, 25, 25-29. [CrossRef] [PubMed]

38. Kosová, K.; Vítámvás, P.; Prášil, I.T.; Renaut, J. Plant proteome changes under abiotic stress-contribution of proteomics studies to understanding plant stress response. J. Proteom. 2011, 74, 1301-1322. [CrossRef] [PubMed]

39. Zhang, H.; Han, B.; Wang, T.; Chen, S.; Li, H.; Zhang, Y.; Dai, S. Mechanisms of plant salt response: Insights from proteomics. J. Proteome Res. 2012, 11, 49-67. [CrossRef] [PubMed] 
40. Kaufmann, K.; Smaczniak, C.; de Vries, S.; Angenent, G.C.; Karlova, R. Proteomics insights into plant signaling and development. Proteomics 2011, 11, 744-755. [CrossRef] [PubMed]

41. Palma, J.M.; Corpas, F.J.; del Río, L.A. Proteomics as an approach to the understanding of the molecular physiology of fruit development and ripening. J. Proteom. 2011, 74, 1230-1243. [CrossRef] [PubMed]

42. Szymanski, J.; Levin, Y.; Savidor, A.; Breitel, D.; Chappell-Maor, L.; Heinig, U.; Töpfer, N.; Aharoni, A. Label-free deep shotgun proteomics reveals protein dynamics during tomato fruit tissues development. Plant. J. 2017, 90, 396-417. [CrossRef] [PubMed]

43. Baerenfaller, K.; Grossmann, J.; Grobei, M.A.; Hull, R.; Hirsch-Hoffmann, M.; Yalovsky, S.; Zimmermann, P.; Grossniklaus, U.; Gruissem, W.; Baginsky, S. Genome-scale proteomics reveals Arabidopsis thaliana gene models and proteome dynamics. Science 2008, 320, 938-941. [CrossRef] [PubMed]

44. Mintz-Oron, S.; Mandel, T.; Rogachev, I.; Feldberg, L.; Lotan, O.; Yativ, M.; Wang, Z.; Jetter, R.; Venger, I.; Adato, A.; et al. Gene expression and metabolism in tomato fruit surface tissues. Plant. Physiol. 2008, 147, 823-851. [CrossRef] [PubMed]

45. Famiani, F.; Battistelli, A.; Moscatello, S.; Cruz-Castillo, J.G.; Walker, R.P. The organic acids that are accumulated in the flesh of fruits: Occurrence, metabolism and factors affecting their contents-a review. Rev. Chapingo Ser. Hortic. 2015, 21, 97-128. [CrossRef]

46. Hockema, B.R.; Etxeberria, E. Metabolic contributors to drought-enhanced accumulation of sugars and acids in oranges. J. Am. Soc. Hortic. Sci. 2001, 126, 599-605. [CrossRef]

47. Yang, J.; Zhu, L.; Cui, W.; Zhang, C.; Li, D.; Ma, B.; Cheng, L.; Ruan, Y.L.; Ma, F.; Li, M. Increased activity of MdFRK2, a high-affinity fructokinase, leads to upregulation of sorbitol metabolism and downregulation of sucrose metabolism in apple leaves. Hortic. Res. 2018, 5, 71. [CrossRef] [PubMed]

48. Givan, C.V. Evolving concepts in plant glycolysis: Two centuries of progress. Biol. Rev. 1999, 74, $277-309$. [CrossRef]

49. Yao, Y.X.; Li, M.; Zhai, H.; You, C.X.; Hao, Y.J. Isolation and characterization of an apple cytosolic malate dehydrogenase gene reveal its function in malate synthesis. J. Plant. Physiol. 2011, 168, 474-480. [CrossRef] [PubMed]

50. Pua, E.C.; Chandramouli, S.; Han, P.; Liu, P. Malate synthase gene expression during fruit ripening of Cavendish banana (Musa acuminata cv. Williams). J. Exp. Bot. 2003, 54, 309-316. [CrossRef] [PubMed]

51. Terrier, N.; Glissant, D.; Grimplet, J.; Barrieu, F.; Abbal, P.; Couture, C.; Ageorges, A.; Atanassova, R.; Léon, C.; Renaudin, J.P.; et al. Isogene specific oligo arrays reveal multifaceted changes in gene expression during grape berry (Vitis vinifera L.) development. Planta 2005, 222, 832-847. [CrossRef] [PubMed]

52. Martinoia, E.; Maeshima, M.; Neuhaus, H.E. Vacuolar transporters and their essential role in plant metabolism. J. Exp. Bot. 2007, 58, 83-102. [CrossRef] [PubMed]

53. Ma, B.; Liao, L.; Fang, T.; Peng, Q.; Ogutu, C.; Zhou, H.; Ma, F.; Han, Y. A Ma10 gene encoding P-type ATPase is involved in fruit organic acid accumulation in apple. Plant. Biotechnol. J. 2019, 17, 674-686. [CrossRef] [PubMed]

54. Etienne, C.; Moing, A.; Dirlewanger, E.; Raymond, P.; Monet, R.; Rothan, C. Isolation and characterization of six peach cDNAs encoding key proteins in organic acid metabolism and solute accumulation: Involvement in regulating peach fruit acidity. Physiol. Plant. 2002, 114, 259-270. [CrossRef] [PubMed]

55. Yang, L.T.; Xie, C.Y.; Jiang, H.X.; Chen, L.S. Expression of six malate-related genes in pulp during the fruit development of two loquat (Eriobotrya japonica) cultivars differing in fruit acidity. Afr. J. Biotechnol. 2011, 10, 2414-2422.

56. Wiśniewski, J.R.; Zougman, A.; Mann, M. Combination of FASP and StageTip-based fractionation allows in-depth analysis of the hippocampal membrane proteome. J. Proteome Res. 2009, 8, 5674-5678. [CrossRef] [PubMed]

57. Cox, J.; Mann, M. MaxQuant enables high peptide identification rates, individualized ppb-range mass accuracies and proteome-wide protein quantification. Nat. Biotechnol. 2008, 26, 1367. [CrossRef] [PubMed]

58. Kanehisa, M.; Goto, S.; Sato, Y.; Furumichi, M.; Tanabe, M. KEGG for integration and interpretation of largescale molecular data sets. Nucleic Acids Res. 2012, 40, D109-D114. [CrossRef] [PubMed]

(C) 2019 by the authors. Licensee MDPI, Basel, Switzerland. This article is an open access article distributed under the terms and conditions of the Creative Commons Attribution (CC BY) license (http://creativecommons.org/licenses/by/4.0/). 